\title{
PENGARUH KOMPETENSI, LINGKUNGAN, MOTIVASI, DISIPLIN, KEPEMIMPINAN DAN KOMUNIKASI TERHADAP PRODUKTIVITAS KERJA KARYAWAN PT.RADIATEX PEKALONGAN
}

\author{
Ririn Anggraini ${ }^{1}$, Muhamad Yusuf ${ }^{2}$, R.Irawan Supriyatno ${ }^{3}$ \\ 1 Program Studi Manajemen FEB UMPP \\ ${ }^{2}$ Program Studi Akuntansi FEB UMPP \\ 3Program Studi Manajemen FEB UMPP \\ r.irawanstiem@gmail.com
}

\begin{abstract}
ABSTRAK
Penelitian atau studi terjadi bermaksud mendapati: pengaruh kompetensi, lingkungan kerja, motivasi kerja, disiplin kerja, kepemimpinan dan komunikasi secara sebagian-sebagian dan bersamaa-sama terhadap produktivitas kerja. Metode studi menggunakan asosiatif kausal melalui pendekatan kuantitatif yang dilakukan pada PT. Radiatex Pekalongan. Teknik yang digunakan untuk memperoleh bukti melalui kuesioner serta diuji validitas reliabilitasnya. Populasi berfokus atas karyawan karyawan divisi produksi di PT. Radiatex Pekalongan, dengan sampel sebanyak 70. Hasil memanifestasikan berupa Kompetensi, Lingkungan Kerja, Motivasi Kerja, Disiplin Kerja, Kepemimpinan dan Komunikasi secara terpisah dan bersamaan mempunyai pengaruh terhadap produktivitas kerja karyawan. Kondisi ini berdasarkan hasil uji-t dan uji-f yang mencapai nilai signifikansi dibawah 0,05.

Kata Kompetensi, Lingkungan Kerja, Motivasi Kerja, Disiplin Kerja, Kunci : $\quad$ Kepemimpinan, Komunikasi, Produktivitas Kerja
\end{abstract}

\author{
THE EFFECT OF COMPETENCE, ENVIRONMENT, MOTIVATION, \\ DISCIPLINE, LEADERSHIP AND COMMUNICATION ON EMPLOYEE \\ WORK PRODUKTIVITY OF RADIATEX LTD. PEKALONGAN
}

\begin{abstract}
This research aim on analyzing: the effect of competence, work environment, work motivation, work discipline, leadership and communication simultaneously and partially to the employee work productivity. A causal associative study was used quantitative approach conducted at PT. Radiatex Pekalongan. this study used a valid and reliable questionnnaire. A sampling method used simple random sampling method. Seventy employees of the production department at Radiatex Ltd. Pekalongan participated in this study. The result of this study are competence, work environment, work motivation, work discipline, leadership and communication partially and simultaneously have a significant effect on employee work productivity. The statistical test showed $t$-test and F-test had significant value less than 0.05 .
\end{abstract}

Keywords : Competence, Work Environment, Work Motivation, Work Discipline, Leadership, Communication, Work Productivity Employee 


\section{PENDAHULUAN}

Sumber daya yang terdapat di perusahaan meliputi modal, teknologi, metode atau strategi, manusia (tenaga kerja) dan sumber daya lainnya. Tenaga kerja atau karyawan merupakan suatu komponen yang paling dominan. Karyawan atau pekerja di perusahaan yang kapabel, cakap, serta kompeten diukur melalui hasil produktivitas kerjanya.

Produktivitas kerja dipengaruhi salah satu komponen yaitu kompetensi dimiliki oleh karyawan atau pekerja. Kompetensi tenaga kerja PT. Radiatex Pekalongan tergolong sudah cukup baik tetapi masih perlu peningkatan terutama dari segi latar belakang pendidikan calon karyawan dalam proses perekrutan karyawan.

Dalam menghasilkan produktivitas kerja karyawan yang tinggi tidak sesederhana untuk dilakukan oleh perusahaan, faktor lain yang mempengaruhinya yaitu lingkungan kerja. PT. Radiatex Pekalongan memiliki lingkungan kerja mesti diperlukan peningkatan karena masih adanya karyawan yang merasa kurang tenteram dan senang dalam bekerja karena terganggu oleh cahaya penerangan baik berupa lampu maupun pancaran sinar matahari yang kurang.

Dalam menggubah produktivitas kerja karyawan yang tinggi sukar untuk dilakukan oleh perusahaan, faktor lain yang mempengaruhinya yaitu motivasi kerja. Motivasi yang dimiliki karyawan PT. Radiatex Pekalongan dapat dikatakan mengalami penurunan, hal ini dikarenakan adanya ketidaksesuaian pendapatan dan bonus dengan beban kerja yang dimiliki oleh karyawan. Pendapatan dan bonus yang didapatkan karyawan mengalami penurunan karena adanya pandemi covid-19 yang melemahkan ekonomi.

Dalam menciptakan produktivitas kerja karyawan tidak mudah untuk dilakukan oleh perusahaan, faktor lain yang mempengaruhinya yaitu disiplin kerja. Disiplin kerja karyawan PT. Radiatex Pekalongan semakin mengalami penurunan hal ini disebabkan adanya penurunan pendapatan dan bonus yang dapat menggerakkan karyawan bertugas secara keras sesuai prosedur yang sudah disepakati. Dengan adanya penurunan pendapatan dan bonus mengakibatkan sebagian karyawan atau tenaga kerja mengabaikan peraturan dalam perusahaan seperti keterlambatan datang ke tempat kerja dan memulai proses produksi, serta mangkir dari pekerjaan.

Dalam menciptakan produktivitas kerja karyawan tidak ringan untuk dilakukan oleh perusahaan, faktor lain yang mempengaruhinya yaitu kepemimpinan. Pemimpin yang baik dapat membantu pertumbuhan dan perkembangan bisnis dengan memotivasi karyawanya untuk selalu meningkatkan produktivitas kerja. Prinsip dasar seorang pemimpin adalah rasa hormat. Dimana apabila seorang pemimpin menginginkan karyawan untuk bekerja keras untuk kepentingan perusahaan maka pemimpin harus menyadari tenaga yang telah dikerahkan karyawan dengan melalui tindakan maupun komunikasi. 
Peran komunikasi juga tidak dapat dilepaskan dalam upaya pencapaian peningkatan produktivitas kerja karyawan. Komunikasi yang tercipta di PT Radiatex pekalongan dapat ditetapkan baik dan efektif karena komunikasi yang terjalin tanpa adanya kecanggungan tetapi masih tetap terciptanya rasa hormat selain itu tanpa adanya pemisahan karyawan berdasarkan kelompokkelompok tertentu.

PT. Radiatex Pekalongan berkedudukan di jalan Tangkil Tengah Kecamatan Kedungwuni Kabupaten Pekalongan yang bergerak dalam bidang kreasi sarung bermotif. Bersumberkan pada fakta yang didapatkan pengeluaran produk perusahaan mengalami sedikit peningkatan tetapi mengalami pengurangan hasil produksi yang dratis, permasalahan tersebut dampak ditengah terjadinya pandemi covid-19. Perkara ini disertai dengan terjadinya kecacatan hasil produksi yang mengalami kenaikan. Penurunan hasil produksi dikarenakan karyawan yang kurang kompeten hal ini dampak dari beberapa karyawan yang mengalami perubahan posisi dan mengalami ketidaksesuaian penempatan kerja. Masih terdapat kekurangannyamanan lingkungan kerja yang dialami karyawan seperti penerangan cahaya yang kurang serta dari sisi motivasi kerja dimana adanya pendemi menjadikan pendapatan dan kompensasi menurun yang berdampak pada penurunan tingkat kedisplinan kerja dimana beberapa karyawan yang mengalami keterlambatan dan melanggar aturan yang telah diterapkan perusahaan, Melalui hal ini dibutuhkan kepemimpinan dan komunikasi yang efektif. Berpedoman mengenai permasalahan yang telah dideskripsikan diatas maka peneliti bermaksud meneliti penelitian mengenai adanya pengaruh kompetensi, lingkungan kerja, motivasi kerja, disiplin kerja, kepemimpinan dan komunikasi baik secara tersendiri maupun bersamaan terhadap produktivitas kerja di PT Radiatex Pekalongan.

\section{LANDASAN TEORI DAN PENGEMBANGAN HIPOTESIS PRODUKTIVITAS KERJA}

Dipaparkan oleh Kussrianto (2017, p. 102) sebenarnya produktivitas merupakan tolak ukur antara ouput yang dicapai melalui peranan karyawan (sumber daya) persatuan waktu. Dalam mengukur kenaikan maupun penurunan tingkat produktivitas kerja dibutuhkan suatu indikator-indikator (Prof. Dr. H. Edy Sutrisno, 2017, p. 104), indikator tersebut sebagai berikut:
1. Kemampuan
2. Semangat Kerja
3. Mutu
4. Meningkatkan Hasil yang Dicapai
5. Pengembangan Diri
6. Efisiensi

\section{KOMPETENSI}

Secara literal, menurut Scale kompetensi berawal mula dari istilah competence artinya kapabilitas, keahlian, serta kewenangan (2017, p. 202). 
Pendapat mengenai dekripsi kompetensi dikemukakan oleh Boulter, Dalzier dan Hill (Prof. Dr. H. Edy Sutrisno, 2017, p. 203), mengemukakan pendapat mengenai kompetensi merupakan suatu karakteristik dasar mengenai seseorang yang mengharuskannya memberikan kemampuan unggul dalam aktivitas pekerjaan, peran, atau posisi tertentu.

Sutrisno mengemukakan pendapat bersumberkan atas Gordon (2011, p. 204), dalam mengukur kenaikan maupun penurunan tingkat produktivitas kerja dibutuhkan suatu indikator-indikator kompetensi yang dimiliki pekerja yaitu:

1. Pemahaman (Understanding)

2. Keterampilan (skills)

3. Perilaku (attitude)

4. Minat (Interest)

\section{LINGKUNGAN KERJA}

Reksohadiprojo dan Gitosudarmo (Reksohadiprodjo, Sukanto, \& Gitosudarmo, 2015, p. 151) mengemukakan anggapan bahwa lingkungan kerja yaitu kondisi kawasan aktivitas pekerjaan yang harus diatur sehingga tidak mengacaukan aktivitas para pekerja serta agar didapatkan pertumbuhan produktivitas serta menurunnya pengeluaran produksi setiap tahunnya.

Indikator-indikator yang dapat menilai tingkat lingkungan kerja yang baik menurut Sedarmayati (Sedarmayanti, 2009, p. 28) yaitu:

1. Pencahayaan

2. Temperatur Udara

3. Hubungan antara karyawan dan pimpinan

4. Kondisi Kerja

5. Keamanaan Kerja

\section{MOTIVASI KERJA}

Hasibuan mengemukakan Motivasi mempertanyakan bagaimana cara perusahaan menggerakkan gairah dan semangat karyawan dalam bekerja, sehingga didapatkan karyawan berkenan bertidak sungguh-sungg menggunakan seluruh kecakapan dan keahlian guna memanifestasikan sasarannya (Hasibuan Malayu S.P., 1999). Menurut Hasibuan (2008) indikator dalam menaksir motivasi kerja yang dmiliki karyawan, ialah:

1. Kebutuhan akan penghargaan

2. Kebutuhan fisik

3. Kebutuhan sosial

4. Kebutuhan rasa aman

5. Kebutuhan dorongan mencapai tujuan

\section{DISIPLIN KERJA}

Gagasan yang lebih spesifik mengenai disiplin kerja disampaikan oleh Bedjo Siswanto yang dikutip dalam (Farida \& Hartono, 2015) menurut Bedjo Siswanto mengemukkan pendapat disiplin kerja dapat didefinisikan sebagai 
suatu perilaku tunduk, mematuhi, menjunjung serta berpegang teguh atas aturan atau tatanan yang ditetapkan baik yang tertera maupun tidak tertera beserta mampu mengaplikasikannya dan tidak mengelak jika memperoleh sanksi atau hukuman bilamana dirinya menyalahi tugas dan kewajibannya yang diberikan kepadanya. Dibutuhkan suatu indikator dalam menaksirkan disiplin kerja yang telah diterapkan dan diaplikasikan oleh pekerja yang dikemukakan Malayu (Hasibuan M. , 2006), yaitu:

1. Adanya keterlambatan kerja

2. Seringnya terjadi kesalahan

3. Absensi tenaga kerja

4. Adanya pemogokan

\section{KEPEMIMPINAN}

Kepemimpinan dikemukakan oleh Soetopo Hendiyat dan Soemanto Wasty (Soetopo, Hendyat, \& Soemanto, 1982) menggambarkan tingkah laku yang terdapat didalam pribadi seorang selama menjalin interaksi dan berhubungan pada lingkungan serta bertindak didalamnya guna menggapai sasarannya. Kepemimpinan ditegaskan oleh Nawawi dan Martini (Nawawi \& Martini, 1995) merupakan kemampuan atau kecerdasan mendorong atau merangsang beberapa manusia untuk bekerja secara bersama-sama melakukan aktivitas-aktivitas secara terencana untuk tujuan atau sasaran bersama-sama.

Martoyo (2000, p. 176-179) mengemukakan indikator-indikator yang ada dalam kepemimpinan diantaranya, yaitu:

1. Kemampuan analitis

2. Keterampilan Komunikasi

3. Kemampuan mendengar

4. Ketegasan

\section{KOMUNIKASI}

T. Hani Handoko (2001) mengemukakan pendapatnya tentang komunikasi dimana merupakan cara pengalihan pemahaman dalam struktur inspirasi, pendapat atau penjelasan melalui seseorang kepada orang lain. Sedangkan komunikasi dikemukakan oleh Komala (Karlina, Ardianto, \& Komala, 2009) merupakan suatu metode peralihan informasi dilakukan oleh sesama manusia yang akan saling memberikan pemahaman yang mendalam.

Menurut anggapan Mangkunegara (2000) yang dikutip dalam Rensius indikator-indikator yang terdapat dalam komunikasi, ialah:

1. Kemudahan mendapatkan informasi

2. Efektivitas komunikasi

3. Tingkat pemahaman pesan

4. Perubahan sikap 


\section{KERANGKA PEMIKIRAN}

Kerangka berfikir yang baik akan memaparkan secara berkonsep perhubungan antar variabel yang hendak diteliti, selanjutnya dirumuskan ke dalam bentuk paradigm penelitian.

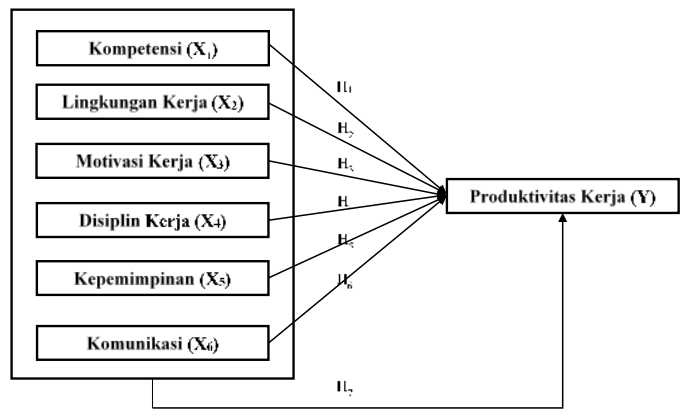

Gambar 1 kerangka berfikir

Sumber: kerangka berfikir yang dirumuskan (2021)

Keterangan:

$\mathrm{H}_{1}$ : adanya pengaruh kompetensi $\left(\mathrm{X}_{1}\right)$ terhadap produktivitas kerja

$\mathrm{H}_{2}$ : adanya pengaruh lingkungan kerja $\left(\mathrm{X}_{2}\right)$ terhadap produktivitas kerja

$\mathrm{H}_{3}$ : adanya pengaruh motivasi kerja $\left(X_{3}\right)$ terhadap produktivitas kerja

$\mathrm{H}_{4}$ : adanya pengaruh disiplin kerja $\left(\mathrm{X}_{4}\right)$ terhadap produktivitas kerja

$\mathrm{H}_{5}$ : andanya pengaruh kepemimpinan $\left(X_{5}\right)$ terhadap produktivitas kerja

$\mathrm{H}_{6}$ : adanya pengaruh komunikasi $\left(\mathrm{X}_{6}\right)$ terhadap produktivitas kerja

$\mathrm{H}_{7}$ : adanya pengaruh semua variabel bebas terhadap produktivitas kerja

\section{PENELITIAN TERDAHULU}

Observasi atau studi dilakukan berjudul "Produktivitas Kerja Karyawan Ditinjau dari Motivasi, Disiplin Kerja dan Lingkungan Kerja pada PT. Iskandar Indah Printing Textile Surakarta" (Baity, Djumali, \& Kustiyah, 2020). Objek observasi atau studi bersumberkan pada produktivitas kerja pekerja PT. Iskandar Indah Printing Textile Surakarta. Jumlah sampel digunakan dalam penelitian ini sebanyak 100 responden. Observasi atau studi menemukan hasil yaitu secara tersendiri maupun bersamaan variabel $X$ yaitu variabel motivasi, variabel disiplin kerja serta variabel lingkungan kerja mempunyai pengaruh terhadap variabel terikat atau produktivitas kerja pada PT. Iskandar Indah Printing Textile Surakarta. Teknik yang digunakan untuk memperoleh bukti dengan interview, kuesioner, pengarsipan serta studi kepustakaan.

\section{METODE PENELITIAN}

Penelitian atau studi dengan menggunakan jenis pengamatan asosiatif kausal melalui pendekatan kuantitatif. Sugiyono (Sugiyono, 2015) mengemukakan bahwa penelitian asosiatif kausal bermaksud memahami terdapatnya pengaruh, dampak, hubungan atau akibat antara variabel independen atas variabel dependen, kuat maupun eratnya kaitan pengaruhnya serta berfaedah atau tidak pengaruh atau hubungan tersebut. 


\section{Tempat penelitian}

Tempat penelitian diadakannya pengkajian, pendalaman dan telaah permasalahan di PT. Radiatex Pekalongan yang berlokasi di Jalan Raya Tangkil Tengah Kecamatan Kedungwuni Kabupaten Pekalongan, yang dilaksanakan pengamatan pada tahun 2021.

\section{Populasi dan Sampel Penelitian}

Populasi berfokus pada pekerja produksi di PT Radiatex Pekalongan sebanyak 85 pekerja. Sampel yang menyubstitusi populasi perlu betul-betul mewakili. Dalam menentukan jumlah sampel dari populasi dengan rumus slovin, dimana perhitungan tersebut ketika populasi di dalam penelitian telah diketahui jumlahnya.

$$
n=\frac{85}{\left(1+85 \times 0,05^{2}\right)}=70
$$

Berdasarkan perhitungan maka jumlah sampel dari populasi yang digunakan sebagai responden berjumlah 70 responden. Guna mempercepat serta mempermudah proses perhitungan data dengan bantuan software SPSS v.25.

\section{Data, Instrumen dan Teknik Pengumpulan Data}

Prosedur perolehan bukti data adalah dengan menerapkan sumber data baik berupa sumber primer maupun sumber sekunder. Data utama atau primer dalam penelitian ini berupa observasi yaitu melakukan pemantauan secara langsung atas gejala atau fenomena penelitian guna mencapai bukti akurat, sesuai dan pasti, interview yaitu guna menangkap informasi dengan akurat dan tepat menyelenggarakan tanya jawab lansung dari pimpinan dan karyawan perusahaan dan kuesioner dengan skor pengukuran dengan menggunakan skala likert guna memperoleh dan menjumpai bahan maupun informasi yang relevan, dengan penyebaran susunan pernyataan yang kemudian untuk dijawab oleh responden. Prosedur perolehan data atau bukti sampel melalui simple random sampling. Data sekunder berupa literatur atau pustaka acuan untuk memenuhi dan menyempurnakan bukti data, yakni menggunakan buku atau bacaan yang berkaitan dan jurnal berkenaan tentang penelitian terkait serta melalui media internet berupa website berkenaan untuk proses pengkajian.

\section{Teknik Analisis Data}

Pengkajian atau penjabaran data menggambarkan deskripsi atau gambaran berkenaan responden bersumber pada tanggapan yang telah didistribusikan melalui persoalan-persoalan dalam kuesioner. Analisis atau penjabaran dilakukan melalui penafsiran data yang didapatkan melalui lembar kuesioner yang disusun secara terorganisir dalam struktur tabel frekuensi proporsi sehingga mampu ditarik kesimpulan. Penjabaran kuantitatif digunakan guna mengelola data yang didapatkan melalui kuesioner yang telah 
diolah dalam bentuk angka dan dianalisis dengan perhitungan statistik, dengan menggunakan software SPSS v.25.

\section{HASIL DAN PEMBAHASAN}

Statistika Deskriptif

Tabel 1 Pengujian Statistika Deskriptif

\begin{tabular}{|l|r|r|r|r|r|}
\hline \multicolumn{7}{|c|}{ Descriptive Statistics } \\
\hline & \multicolumn{1}{|c|}{ Min } & \multicolumn{1}{c|}{ Max } & Mean & Std. Deviasi \\
\hline Kompetensi (X1) & 70 & 12 & 20 & 15.53 & 2.083 \\
\hline $\begin{array}{l}\text { Lingkungan Kerja } \\
(X 2)\end{array}$ & 70 & 14 & 24 & 18.81 & 2.195 \\
\hline Motivasi Kerja (X3) & 70 & 8 & 25 & 18.80 & 2.962 \\
\hline Disiplin Kerja (X4) & 70 & 8 & 20 & 14.89 & 2.464 \\
\hline Kepemimpinan (X5) & 70 & 12 & 20 & 15.84 & 1.990 \\
\hline Komunikasi (X6) & 70 & 8 & 20 & 15.44 & 2.387 \\
\hline $\begin{array}{l}\text { Produktivitas Kerja } \\
\text { (Y) }\end{array}$ & 70 & 20 & 29 & 25.41 & 1.861 \\
\hline Valid N (listwise) & 70 & & & & \\
\hline
\end{tabular}

Sumber: Pengolahan data utama (2021)

Penjelasan mengenai statistika deskriptif mencakup angka atau nilai terkecil atau terendah, angka atau nilai tertinggi atau terbesar, rerata serta standar deviasi.

\section{Pengujian Validitas}

Validitas secara umum yaitu mengukur apa yang seharusnya diukur. Signifikansi dikatakan absah (valid) ketika r-hitung $>$ r-tabel. Perolehan pengukuran validitas dalam penelitian ini sebagai berikut:

Tabel 2 Pengujian Validitas

\begin{tabular}{|c|c|c|c|c|}
\hline \multirow{2}{*}{ Variabel } & Pernyataan & $\begin{array}{c}\text { r- } \\
\text { hitung }\end{array}$ & Tanda & r-tabel \\
\hline \multirow{4}{*}{ Kompetensi } & $\mathrm{X} 1.1$ & 0,738 & $>$ & 0,235 \\
\cline { 2 - 5 } & $\mathrm{X} 1.2$ & 0,761 & $>$ & 0,235 \\
\cline { 2 - 5 } & $\mathrm{X} 1.3$ & 0,648 & $>$ & 0,235 \\
\cline { 2 - 5 } & $\mathrm{X} 1.4$ & 0,455 & $>$ & 0,235 \\
\hline \multirow{4}{*}{$\begin{array}{c}\text { Lingkungan } \\
\text { Kerja }\end{array}$} & $\mathrm{X} 2.1$ & 0,592 & $>$ & 0,235 \\
\cline { 2 - 5 } & $\mathrm{X} 2.2$ & 0,443 & $>$ & 0,235 \\
\cline { 2 - 5 } & $\mathrm{X} 2.3$ & 0,536 & $>$ & 0,235 \\
\cline { 2 - 5 } & $\mathrm{X} 2.4$ & 0,485 & $>$ & 0,235 \\
\hline \multirow{4}{*}{ Motivasi Kerja } & $\mathrm{X} 3.1$ & 0,648 & $>$ & 0,235 \\
\cline { 2 - 5 } & $\mathrm{X} 3.2$ & 0,622 & $>$ & 0,235 \\
\cline { 2 - 5 } & $\mathrm{X} 3.3$ & 0,653 & $>$ & 0,235 \\
\cline { 2 - 5 } & $\mathrm{X} 3.4$ & 0,742 & $>$ & 0,235 \\
\hline
\end{tabular}




\begin{tabular}{|c|c|c|c|c|}
\hline & $\mathrm{X} 3.5$ & 0,662 & $>$ & 0,235 \\
\hline \multirow{4}{*}{ Disiplin Kerja } & $\mathrm{X} 4.1$ & 0,688 & $>$ & 0,235 \\
\cline { 2 - 5 } & $\mathrm{X} 4.2$ & 0,684 & $>$ & 0,235 \\
\cline { 2 - 5 } & $\mathrm{X} 4.3$ & 0,654 & $>$ & 0,235 \\
\cline { 2 - 5 } & $\mathrm{X} 4.4$ & 0,645 & $>$ & 0,235 \\
\hline \multirow{4}{*}{ Kepemimpinan } & $\mathrm{X} 5.1$ & 0,517 & $>$ & 0,235 \\
\cline { 2 - 5 } & $\mathrm{X} 5.2$ & 0,743 & $>$ & 0,235 \\
\cline { 2 - 5 } & $\mathrm{X} 5.3$ & 0,740 & $>$ & 0,235 \\
\cline { 2 - 5 } & $\mathrm{X} 5.4$ & 0,584 & $>$ & 0,235 \\
\hline \multirow{4}{*}{ Komunikasi } & $\mathrm{X} 6.1$ & 0,778 & $>$ & 0,235 \\
\cline { 2 - 5 } & $\mathrm{X} 6.2$ & 0,827 & $>$ & 0,235 \\
\cline { 2 - 5 } & $\mathrm{X} 6.3$ & 0,818 & $>$ & 0,235 \\
\cline { 2 - 5 } & $\mathrm{X} 6.4$ & 0,789 & $>$ & 0,235 \\
\hline \multirow{4}{*}{$\begin{array}{l}\text { Produktivitas } \\
\text { Kerja }\end{array}$} & $\mathrm{Y} .1$ & 0,464 & $>$ & 0,235 \\
\cline { 2 - 5 } & $\mathrm{Y} .2$ & 0,605 & $>$ & 0,235 \\
\cline { 2 - 5 } & $\mathrm{Y} .3$ & 0,562 & $>$ & 0,235 \\
\cline { 2 - 5 } & $\mathrm{Y} .5$ & 0,541 & $>$ & 0,235 \\
\cline { 2 - 5 } & $\mathrm{Y} .6$ & 0,264 & $>$ & 0,235 \\
\hline
\end{tabular}

Sumber: Data primer diolah (2021)

Seluruh indikator pernyataan kuesioner pada Variabel bebas atau independen maupun terikat atau dependen bersifat absah (valid) dikarenakan memperoleh nilai r-hitung > r-tabel Artinya kuesioner mampu mengukur apa yang seharusnya diukur.

\section{Pengujian Reliabilitas}

Reliabilitas memperlihatkan kestabilan pengukuran yang dilakukan serta erat kaitannya dengan akuransi pengukuran. Variabel pada penelitian dinyatakan stabil atau memperlihatkan hasil yang sama pada waktu yang berbeda ketika memperoleh nilai Cronbach Alpha $>0,60$. Pengujian atau pengukuran reliabilitas dalam penelitian ini sebagai berikut :

Tabel 3 Pengujian Reliabilitas

\begin{tabular}{|l|c|c|c|}
\hline \multicolumn{1}{|c|}{ Variabel } & $\begin{array}{c}\text { Cronbach } \\
\text { Alpha }\end{array}$ & Tanda & Kriteria \\
\hline Kompetensi & 0,757 & $>$ & 0,60 \\
\hline Lingkungan Kerja & 0,694 & $>$ & 0,60 \\
\hline Motivasi Kerja & 0,760 & $>$ & 0,60 \\
\hline Disiplin Kerja & 0,762 & $>$ & 0,60 \\
\hline Kepemimpinan & 0,753 & $>$ & 0,60 \\
\hline Komunikasi & 0,816 & $>$ & 0,60 \\
\hline Produktivitas Kerja & 0,669 & $>$ & 0,60 \\
\hline
\end{tabular}

Sumber: Data primer diolah (2021) 
Hasil perhitungan reliabilitas dengan melihat output cronbach's Alpha mengungkapkan hasil $>0,60$, Membuktikan semua variabel dinyatakan reliabel.

\section{Uji Normalitas}

Dalam menemukan normalitas pada data dalam penelitian dilakukan melalui pengujian Kolmogorov Smirnov. Untuk lebih jelasnya normalitas pada data dari pengujian normalitas berikut ini:

Tabel 4 Pengujian Uji Normalitas

\section{One-Sample Kolmogorov-Smirnov Test}

\begin{tabular}{llr} 
& & \multicolumn{1}{c}{$\begin{array}{c}\text { Unstandardized } \\
\text { Residual }\end{array}$} \\
\hline $\mathrm{N}$ & & 70 \\
\hline Normal Parameters & & Mean \\
\cline { 2 - 3 } & Std. Deviation & 1.43852658 \\
\hline \multirow{2}{*}{ Most Extreme Differences } & Absolute & .060 \\
\cline { 2 - 3 } & Positive & .066 \\
\cline { 2 - 3 } & Negative & -.060 \\
\hline Test Statistic & & .066 \\
\hline Asymp. Sig. (2-tailed) & & $.200^{\mathrm{c}, \mathrm{d}}$ \\
\hline
\end{tabular}
a. Test distribution is Normal.
b. Calculated from data.
c. Lilliefors Significance Correction.
d. This is a lower bound of the true significance.

Sumber: Pengolahan data utama (2021)

Uji Kolmogorov Smirnov diperoleh nilai residual 0,200 > 0,05 maka dinyatakan kesimpulan yag berarti nilai residual terdistribusi secara normal.

\section{Uji Multikolinearitas}

Hasil pengujian multikolinearitas yang telah dilakukan dalam penelitian telah diinterpretasikan sebagai berikut:

Tabel 5 Uji Multikolinearitas

\begin{tabular}{|c|c|c|c|}
\hline \multicolumn{4}{|c|}{ Coefficients ${ }^{a}$} \\
\hline \multirow{2}{*}{\multicolumn{2}{|c|}{ Model }} & \multicolumn{2}{|c|}{ Collinearity Statistics } \\
\hline & & Tolerance & VIF \\
\hline \multirow[t]{7}{*}{1} & (Constant) & & \\
\hline & Kompetensi & .886 & 1.129 \\
\hline & Lingkungan Kerja & .900 & 1.111 \\
\hline & Motivasi Kerja & .913 & 1.096 \\
\hline & Disiplin Kerja & .952 & 1.051 \\
\hline & Kepemimpinan & .959 & 1.043 \\
\hline & Komunikasi & .867 & 1.154 \\
\hline
\end{tabular}

Sumber: Pengolahan data utama (2021) 
Pengujian multikolinearitas diketahui bahwa semua nilai Tolerance $>0,10$ sedangkan untuk nilai VIF memperlihatkan output $<10,00$, maka memperoleh kesimpulan tidak terdapat multikolinearitas antar variabel bebas atau independen yang digunakan.

\section{Pengujian Heteroskesdastisitas}

Pengujian heteroskesdastisitas dengan menggunakan metode Glejser. Berikut hasil pengujian heteroskesdastisitas pada penelitian ini:

Tabel 6 Uji Heteroskesdastisitas

\begin{tabular}{|c|c|c|c|c|c|c|}
\hline \multicolumn{7}{|c|}{ Coefficients $^{\mathrm{a}}$} \\
\hline & & \multicolumn{2}{|c|}{$\begin{array}{l}\text { Unstandardized } \\
\text { Coefficients }\end{array}$} & \multirow{2}{*}{\begin{tabular}{|c|}
$\begin{array}{c}\text { Standardize } \\
\mathrm{d} \\
\text { Coefficients }\end{array}$ \\
Beta \\
\end{tabular}} & \multirow[b]{2}{*}{$\mathrm{T}$} & \multirow[b]{2}{*}{ Sig. } \\
\hline \multicolumn{2}{|c|}{ Model } & B & $\begin{array}{l}\text { Std. } \\
\text { Error }\end{array}$ & & & \\
\hline & (Constant) & -2.583 & 1.768 & & -1.462 & .149 \\
\hline & Kompetensi (X1) & .084 & .053 & .202 & 1.593 & .116 \\
\hline & $\begin{array}{l}\text { Lingkungan Kerja } \\
\text { (X2) }\end{array}$ & .002 & .050 & .006 & .045 & .964 \\
\hline & Motivasi Kerja (X3) & .051 & .037 & .175 & 1.401 & .166 \\
\hline & Disiplin Kerja (X4) & .049 & .043 & .140 & 1.144 & 257 \\
\hline & Kepemimpinan (X5) & .011 & .053 & .024 & .199 & .843 \\
\hline & Komunikasi (X6) & .033 & .047 & .091 & .707 & .482 \\
\hline
\end{tabular}

Sumber: Pengolahan data utama (2021)

Pengujian heteroskesdastisitas menunjukkan bahwa tingkat signifikansi semua hubungan $>0,05$. Keadaan tersebut menunjukkan bahwa paradigma regresi yang digunakan tidak mengalami indikasi heteroskesdastisitas.

\section{Uji Regresi Linier Berganda}

Uji regresi linier berganda bersumber pada perhitungan menggunakan SPSS v.25 menghasilkan persamaan regresi berikut:

Tabel 7 Analisis Regresi Linier Berganda

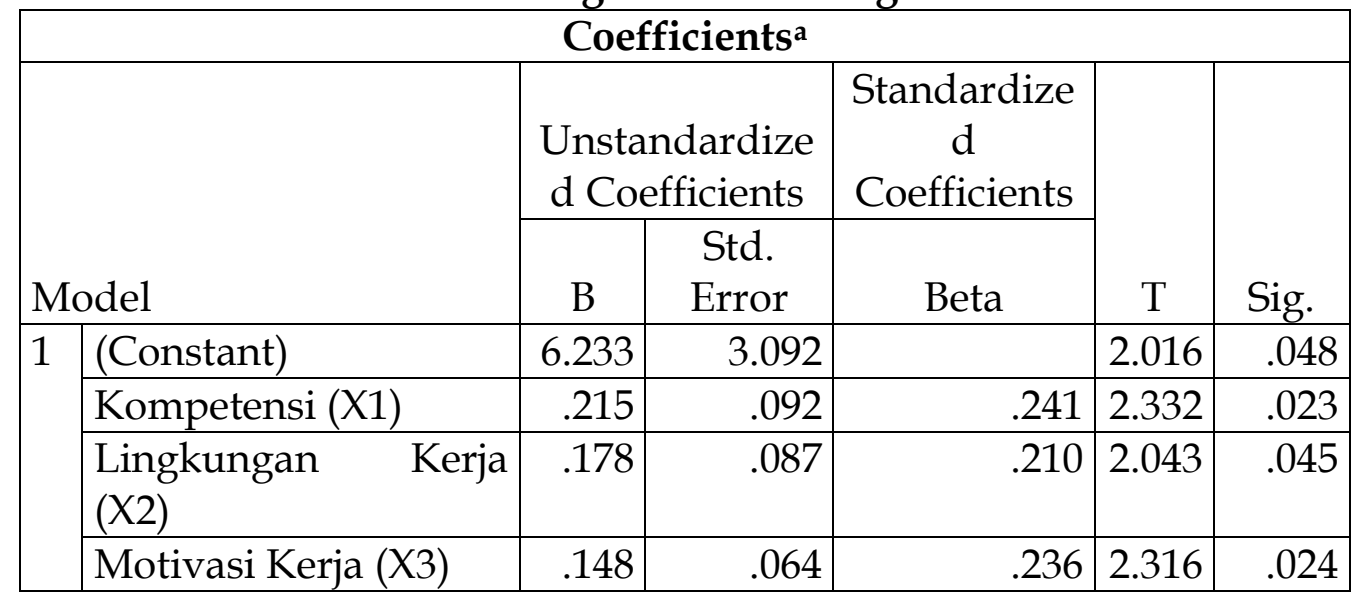




\begin{tabular}{|l|l|r|r|r|r|r|}
\hline Disiplin Kerja (X4) & .264 & .075 & .350 & 3.503 & .001 \\
\hline Kepemimpinan (X5) & .204 & .093 & .218 & 2.196 & .032 \\
\hline Komunikasi (X6) & .164 & .082 & .211 & 2.015 & .048 \\
\hline
\end{tabular}

a. Dependent Variable: Produktivitas Kerja (Y)

Sumber: Data primer diolah (2021)

Rumus persamaan regresi linier berganda :

$Y=6.233+0.215 X_{1}+0.178 X_{2}+0.148 X_{3}+0.264 X_{4}+0.204 X_{5}+0.164 X_{6}$

\section{Uji Parsial (Uji t)}

Uji-t ini menunjukkan adanya pengaruh atau hubungan mengenai masing-masing variabel $(X)$ terhadap variabel $(Y)$. Mengenai hasil perhitungan uji-t yang telah diteliti sebagai berikut:

Tabel 8 Uji Parsial (Uji t)

\begin{tabular}{|c|c|c|c|c|c|c|}
\hline \multicolumn{7}{|c|}{ Coefficients ${ }^{a}$} \\
\hline & & \multicolumn{2}{|c|}{$\begin{array}{l}\text { Unstandardized } \\
\text { Coefficients }\end{array}$} & \multirow{2}{*}{\begin{tabular}{|c|}
$\begin{array}{c}\text { Standardize } \\
\mathrm{d} \\
\text { Coefficients }\end{array}$ \\
Beta
\end{tabular}} & \multirow[b]{2}{*}{$\mathrm{T}$} & \multirow[b]{2}{*}{ Sig. } \\
\hline Model & del & B & $\begin{array}{l}\text { Std. } \\
\text { Error }\end{array}$ & & & \\
\hline \multirow[t]{7}{*}{1} & (Constant) & 6.233 & 3.092 & & 2.016 & .048 \\
\hline & Kompetensi (X1) & .215 & .092 & .241 & 2.332 & .023 \\
\hline & $\begin{array}{l}\text { Lingkungan Kerja } \\
\text { (X2) }\end{array}$ & .178 & .087 & .210 & 2.043 & .045 \\
\hline & Motivasi Kerja (X3) & .148 & .064 & .236 & 2.316 & .024 \\
\hline & Disiplin Kerja (X4) & .264 & .075 & .350 & 3.503 & .001 \\
\hline & Kepemimpinan (X5) & .204 & .093 & .218 & 2.196 & .032 \\
\hline & Komunikasi (X6) & .164 & .082 & .211 & 2.015 & .048 \\
\hline
\end{tabular}

Sumber: Pengolahan data utama (2021)

Pengujian parsial (uji t) mengungkapkan nilai signifikansi semua variabel independen $<0,05$ serta angka t-hitung $>\mathrm{t}$-tabel 1.995, sehingga dapat di simpulkan adanya pengaruh variabel $X$ terhadap variabel produktivitas kerja.

\section{Uji Simultan (Uji-F)}

Digunakan untuk mengungkapkan bahwa secara keseluruhan variabel independen yang digunakan memiliki pengaruh bersamaan terhadap varaibel dependen. Pengujian dengan significance level 5\%. Adapun hasil pengujian uji-f dalam penelitian sebagai berikut: 
Tabel 9 Pengujian Simultan (uji-f)

ANOVA $^{\mathrm{a}}$

\begin{tabular}{llr|r|r|r|r} 
& Sum of Squares & df & Mean Square & F & Sig. \\
\hline 1 & Regression & 96.200 & 6 & 16.033 & 7.074 & $.000^{\mathrm{b}}$ \\
\cline { 2 - 7 } & Residual & 142.786 & 63 & 2.266 & & \\
\cline { 2 - 7 } & Total & 238.986 & 69 & & & \\
\hline
\end{tabular}

a. Dependent Variable: Produktivitas Kerja (Y)

b. Predictors: (Constant), Komunikasi (X6), Motivasi Kerja (X3), Kepemimpinan (X5), Disiplin Kerja

(X4), Lingkungan Kerja (X2), Kompetensi (X1)

Sumber: Data primer diolah (2021)

Berdasarkan pengujian menghasilkan nilai f-hitung $7.074>$ f-tabel 2.23 serta nilai signifikansi $0,000<0,05$. sehingga dapat disimpulkan bahwa secara simultan adanya pengaruh semua variabel independen penelitian pada produktivitas kerja karyawan di PT. Radiatex Pekalongan.

\section{Pengujian Koefisien Determinasi ( $\left.\mathbf{R}^{2}\right)$}

Nilai $\mathrm{R}^{2}$ Digunakan untuk mendapati besarnya pengaruh semua variabel bebas atau independen $(X)$ terhadap variabel terikat atau dependen $(Y)$.

\section{Tabel 10 Pengujian Koefisien Determinasi}

\section{Model Summary}

\begin{tabular}{|c|c|c|c|c|}
\hline Model & $\mathrm{R}$ & R Square & $\begin{array}{c}\text { Adjusted R } \\
\text { Square }\end{array}$ & $\begin{array}{c}\text { Std. Error of the } \\
\text { Estimate }\end{array}$ \\
\hline 1 & $.634^{a}$ & .403 & .346 & 1.505 \\
\hline
\end{tabular}

a. Predictors: (Constant), Komunikasi (X6), Motivasi Kerja (X3),

Kepemimpinan (X5), Disiplin Kerja (X4), Lingkungan Kerja (X2),

Kompetensi (X1)

Sumber: Data primer diolah (2021)

Nilai $\mathrm{R}^{2}$ yaitu 0,346 atau 34,6\%. Kondisi tersebut membuktikan bahwa variabel $(X)$ yaitu kompetensi, lingkungan kerja, motivasi kerja, disiplin kerja, kepemimpinan dan komunikasi mampu menjelaskan 34,6\% dari varian variabel produktivitas kerja dimana $65,4 \%$ selisihnya dipaparkan sebab faktor berlainan yang tidak diteliti. Ada beberapa penyebab pengaruh produktivitas kerja, misalnya teknologi, kesempatan berprestasi, gizi dan kesehatan, sarana produksi dan lain sebagainya.

\section{SIMPULAN DAN SARAN Kesimpulan}

Studi ini bermaksud untuk menganalisis adanya pengaruh kompetensi, lingkungan kerja, motivasi kerja, disiplin kerja, kepimpinan dan komunikasi terhadap produktivitas kerja karyawan PT. Radiatex Pekalongan guna mendapatkan manfaat akademis dan praktis. Berdasarkan data yang telah dikumpulkan terhadap 70 responden dengan metode penyebaran kuesioner yang berisi pernyataan maupun pertanyaan mengenai permasalahan- 
permasalahan yang didapatkan melalui pengamatan, observasi, pendalaman, pengkajian serta penelaahan serta perhitungan melalui SPSS V.25, sehingga dapat diambil keputusan yaitu:

1. Adanya pengaruh relevan antara variabel kompetensi terhadap produktivitas kerja karyawan PT. Radiatex Pekalongan, keadaan ini berdasarkan interpretas pengujian yang memperoleh nilai signifikansi 0.023 $<0.05$.

2. Adanya pengaruh relevan antara variabel lingkungan kerja terhadap produktivitas kerja karyawan PT. Radiatex Pekalongan, keadaan ini berdasarkan interpretasi pengujian yang memperoleh nilai signifikansi 0.045 $<0.05$.

3. Adanya pengaruh relevan antara variabel motivasi kerja terhadap produktivitas kerja karyawan PT. Radiatex Pekalongan, keadaan ini berdasarkan interpretasi pengujian yang memperoleh nilai signifikansi 0.024 $<0.05$.

4. Adanya pengaruh relevan antara variabel disiplin kerja terhadap produktivitas kerja karyawan PT. Radiatex Pekalongan, keadaan ini berdasarkan interpretasi pengujian yang memperoleh nilai signifikansi 0.001 $<0.05$.

5. Adanya pengaruh relevan antara variabel kepemimpinan terhadap produktivitas kerja karyawan PT. Radiatex Pekalongan, keadaan ini berdasarkan interpretasi pengujian yang memperoleh nilai signifikansi $0.032<0.05$.

6. Adanya pengaruh relevan antara variabel komunikasi terhadap produktivitas kerja karyawan PT. Radiatex Pekalongan, keadaan ini berdasarkan interpretasi pengujian yang memperoleh nilai signifikansi 0.048 $<0.05$.

7. Variabel independen yang terdiri dari kompetensi, lingkungan kerja, motivasi kerja, disiplin kerja, kepemimpinan dan komunikasi berpengaruh secara simultan (bersama-sama) terhadap variabel produktivitas kerja karyawan, keadaan ini dapat dibuktikan dari nilai signifikansi sebesar 0.000 $<0.05$.

\section{Saran}

Bersumber pada penelitian, penulis menganjurkan beberapa saran sebagai berikut:

1. Untuk peningkatan penelitian selepas itu diintensikan mampu memperluas dan mengembangkan aspek pengaruh produktivitas kerja selain yang terdapat didalam penelitian seperti variabel teknologi, gizi dan kesehatan dan lain sebagainya.

2. Peneliti seterusnya dimaksudkan ditunjang dengan melalui metode interview dengan karyawan sehingga mampu memberikan hasil yang sebenarnya. 
3. Peneliti seterusnya dimaksudkan kian menyiapkan waktu dalam memperoleh dan mengakumulasi data berkenaan sehingga observasi mampu dilakukan dengan kian teratur.

\section{REFERENSI}

Baity, K. N., Djumali, D., \& Kustiyah, E. (2020). "Produktivitas Kerja Karyawan Ditinjau dari Motivasi, Disiplin Kerja dan Lingkungan Kerja pada PT. Iskandar Indah Printing Textile Surakarta". Edunomika 04 (01), 69-87.

Farida, U., \& Hartono, S. (2015). Manajemen Sumber Daya Manusia II. Ponorogo: Umpo Press.

Handoko, T. H. (2001). Manajemen Personalia dan Sumber Daya Manusia. Yogyakarta: BPFE.

Hasibuan M. S.P. (1999). Organisasi dan Motivasi (ke-2 ed.). Jakarta: Bumi Aksara.

Hasibuan, M. (2006). Manajemen Dasar, Pengertian dan Masalah (Edisi Revisi ed.). Jakarta: Bumi Aksara.

Karlina, Ardianto, \& Komala. (2009). Komunikasi Massa: Suatu Pengantar (Revisi ed.). Bandung: Ferika Offset.

Mangkunegara, A. A. (2000). Manajemen Sumber Daya Manusia. Bandung: PT. Remaja Rosdakarya.

Nawawi, H., \& Martini, H. (1995). Kepemimpinan yang Efektif. Yogyakarta: Gadjah Mada University Press.

Prof. Dr. H. Edy Sutrisno, M. (2017). Manajemen Sumber Daya Manusia . Jakarta: Kencana.

Reksohadiprodjo, Sukanto, \& Gitosudarmo. (2015). Manajemen Produksi Edisi 4. Yogyakarta.

Sedarmayanti. (2009). Sumber Daya Manusia dan Produktivitas Kerja. Bandung: CV. Mandar Maju.

Soetopo, Hendyat, \& Soemanto, W. (1982). Kepemimpinan dan Supervisi. Jakarta: Bina Aksara.

Sugiyono, P. D. (2015). Metode Penelitian Pendidikan (Pendekatan Kuantitatif, Kualitatif, dan RED). Bandung: Alfabeta. 